\title{
Effects of transplanted adipose derived stem cells on the expressions of $\alpha-S M A$ and DCN in fibroblasts of hypertrophic scar tissues in rabbit ears
}

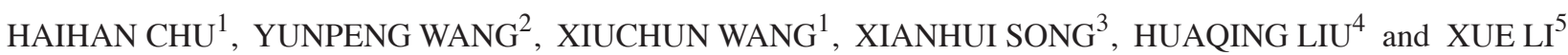 \\ ${ }^{1}$ Department of Burn and Plastic Surgery, Jining First People's Hospital, Jining, Shandong 272000; \\ ${ }^{2}$ Department of Dermatology, Rizhao Hospital of Dermatology, Rizhao, Shandong 276800; \\ ${ }^{3}$ Department of Radiology, Jinan Zhangqiu District Hospital of Traditional Chinese Medicine, Jinan, Shandong 266061; \\ ${ }^{4}$ Department of Neurology and ${ }^{5}$ Health Ward, People's Hospital of Zhangqiu District, Jinan, Shandong 250200, P.R. China
}

Received January 3, 2018; Accepted June 15, 2018

DOI: $10.3892 / \mathrm{etm} .2018 .6383$

\begin{abstract}
To study the effects of transplanted adipose derived stem cells (ADSCs) on the expressions of $\alpha$-smooth muscle actin ( $\alpha$-SMA) and decorin (DCN) in fibroblasts of hypertrophic scar tissues in rabbit ears. Twelve New Zealand white rabbits were selected; the normal subcutaneous adipose tissues in inguinal region were removed, ADSCs were extracted via enzyme digestion, cultured in Dulbecco's modified Eagle's medium (DMEM) and inoculated into the culture dish (3-5x $10^{4}$ cells $\left./ \mathrm{ml}\right)$. After the rabbit ear hypertrophic scar model was established successfully, the fibroblasts of hypertrophic scar tissues in rabbit ears were separated and cultured using the mechanical method combined with enzyme digestion, and the ADSCs and scar fibroblasts were cultured in non-contact Transwell co-culture system for 21 days (experimental group); the corresponding scar fibroblasts were cultured in an ordinary 6-well plate without any treatment for 21 days (control group). The content of collagen I in fibroblasts was detected using the enzyme-linked immunosorbent assay (ELISA) kit, the mRNA expressions of $\alpha$-SMA and DCN were detected via reverse transcription-polymerase chain reaction (RT-PCR), the protein expressions of $\alpha$-SMA and DCN were detected via western blot analysis, and the expressions and distribution of $\alpha$-SMA and DCN were detected via immunofluorescence assay. The results of ELISA showed that the content of collagen I in experimental group was decreased significantly $(\mathrm{p}<0.01)$. The results of RT-PCR and western blot analysis revealed that the mRNA and protein expression levels of $\alpha$-SMA were significantly decreased $(\mathrm{P}<0.01$, but those of $\mathrm{DCN}$
\end{abstract}

Correspondence to: Dr Xiuchun Wang, Department of Burn and Plastic Surgery, Jining First People's Hospital, 6 Jiankang Road, Jining, Shandong 272000, P.R. China

E-mail: shifuzhao77@163.com

Key words: adipose derived stem cells, hypertrophic scar, Transwell co-culture, $\alpha$-SMA/DCN were significantly increased $(\mathrm{p}<0.01)$. Moreover, the results of immunofluorescence assay showed that the expression of $\alpha$-SMA in experimental group was significantly decreased, while the expression of DCN was significantly increased. ADSCs can inhibit the mRNA and protein expressions of $\alpha$-SMA and promote the mRNA and protein expressions of $\mathrm{DCN}$ in in vitro culture system, and they are expected to be used in the prevention and treatment of pathological scars.

\section{Introduction}

Scar is a general term of changes in histopathology and appearance of skin tissues caused by various wounds, and the clinical incidence rate of scar can be as high as $40-70 \%$, especially in the skin burn, postoperative period and trauma (1). Scar generation not only brings the physical and mental pain for patients, but also causes the appearance damage or even dysfunction to relevant tissues. The clinical scar repair in plastic surgery is also an important problem faced by the doctors. At present, the clinical treatment measures and means are not the same due to different types, size and special parts of scars. The most commonly used methods include suture after surgical resection, skin grinding, soft tissue expansion and flap transplantation, and the non-surgical treatment means include laser, drug injection, freezing and compression; however, none of the above methods can thoroughly cure the scar. In addition, these treatment methods also have their own limitations and different degrees of adverse reactions (2). A large number of studies have shown that there is a kind of stem cell in adipose tissues, namely the adipose derived stem cells (ADSCs) that still retain the differentiation potential $(2,3)$. ADSCs have the functions of synthesis and secretion of a variety of cell growth factors $(4,5)$, and these cytokines can act on fibroblasts and affect the synthesis and metabolism of collagen and other extracellular matrixes $(6,7)$, so it is inferred that ADSCs can inhibit the fibrosis of scar fibroblasts in in vitro culture system.

To investigate the effects of transplanted ADSCs on the expressions of $\alpha$-smooth muscle actin ( $\alpha$-SMA) and decorin (DCN) in fibroblasts of hypertrophic scar tissues in rabbit ears, ADSCs and hypertrophic scar fibroblasts were 
co-cultured in vitro in this study, so as to provide theoretical support for the new clinical treatment mechanism of hypertrophic scar tissues.

\section{Materials and methods}

Materials. Dulbecco's modified Eagle's medium (DMEM), fetal bovine serum (FBS), trypsin and ethylenediaminetetraacetic acid (EDTA) (Invitrogen; Thermo Fisher Scientific, Inc., Waltham, MA, USA); $\alpha$-SMA and DCN primer sequences (Beijing Sunbiotech Co. Ltd., Beijing, China); immunofluorescence kit (Corning Incorporated, Corning, NY, USA); primary antibodies: Rabbit monoclonal anti- $\alpha$-SMA and rabbit polyclonal to Decorin $(1: 1,000$; cat. nos. ab150301 and ab137508 respectively, both obtained from Abcam, (Cambridge, MA, USA); secondary antibody, goat anti-mouse IgG-HRP (1:2,000; cat. no. ab6789; Abcam); enzyme-linked immunosorbent assay (ELISA) kit, bicinchoninic acid (BCA) protein quantification kit and cell lysis buffer (Beyotime Institute of Biotechnology, Haimen, China).

Establishment of rabbit ear scar model. Twelve male adult New Zealand white rabbits weighing between 2.5 and $3.5 \mathrm{kgs}$ were purchased from Laboratory Animal Center of Jining First People's Hospital (Jining, China). The animals were single-housed under standard conditions at $22 \pm 2^{\circ} \mathrm{C}$ with a $12 \mathrm{~h}$ light/dark cycle and fed ad libitum. Rabbits were accommodated to the holding room for at least 1 week before the initiation of experiments. All rabbit experiments were designed to minimize suffering and reduce the number of animals used. Rabbits were anesthetized with intramuscular injection of ketamine $(45 \mathrm{mg} / \mathrm{kg})$ and xylazine $(5 \mathrm{mg} / \mathrm{kg})$. Rabbit ears were pressed slightly, and the red mark could be seen but the skin was not damaged. The skin was cut along the red mark using the scalpel without damaging the ear cartilage; the whole round skin was removed and the subcutaneous tissue and cartilage membrane were peeled off in operation, and the integrity of cartilage surface was maintained. The wound was pressed using gauze for $5 \mathrm{~min}$ to prevent excessive bleeding. After the operation without bleeding in wound any longer, the erythromycin eye ointment was wiped on each wound. After operation, penicillin and chloramphenicol were used in a timely manner; if there was wound infection or even necrosis, it should be promptly removed. Animal treatments were carried out in line with the international ethical clauses concerning the Care and Use of Laboratory Animals of Jining First People's Hospital, and performed in accordance with the Guidelines for Laboratory Animals of the National Research Council of USA (1996).

Extraction and culture of ADSCs. After the big-ear rabbits were weighed and anesthetized, the fat in left inguinal fold was removed using eye scissors, peeled off and washed with phosphate buffered saline (PBS) containing antibiotics. Then the fat was placed in the sterile centrifuge tube and cut into pieces. Type I collagenase $(10 \mathrm{ml})(1 \mathrm{mg} / \mathrm{ml})$ was added for digestion in the shaker at $37^{\circ} \mathrm{C}$, followed by centrifugation at $1,000 \mathrm{x} \mathrm{g}$ for $10 \mathrm{~min}$ in the centrifugal machine; then the supernatant was removed, and the culture solution was added into the original centrifuge tube. After the mixture was shaken evenly,
Table I. RT-PCR primer sequences.

\begin{tabular}{lcc}
\hline Genes & $\begin{array}{c}\text { Primer } \\
\text { name }\end{array}$ & \multicolumn{1}{c}{ Primer sequence } \\
\hline$\alpha$-SMA & F & 5'-CCTGAAGAGCATCCCACCCT-3' \\
& R & 5'-CATCCCAGAGTCCAGCACGA-3' \\
DCN & F & 5'-AATAACCGAAATCAAAGATGGAGAC-3' \\
& R & 5'-CGGATTGGTGCCCAGTTCTA-3' \\
$\beta$-actin & F & 5'-TGGCACCCAGCACAATGAA-3' \\
& R & 5'-CTAAGTCATAGTCCGCCTAGAAGCA-3'
\end{tabular}

F, forward; R, reverse.

it was filtered through the 200-mesh gauze and cultured in an incubator with $5 \% \mathrm{CO}_{2}$ at $37^{\circ} \mathrm{C}$. The culture solution (DMEM culture solution containing 10\% FBS) was replaced every other day, followed by passage at a ratio of 1:3.

Scar fibroblast separation and culture. Scar tissues were peeled off with eye scissors and washed thoroughly with PBS containing antibiotics; then they were cut into pieces with surgical scissors and transferred into the centrifugal tube; then dispase $(4 \mathrm{mg} / \mathrm{ml})$ was added for decomposition on the shaker at $37^{\circ} \mathrm{C}$ for $45 \mathrm{~min}$; other methods and steps were the same as those in 1.3.

Co-culture of ADSCs and scar fibroblasts. The third-generation ADSCs cultured were treated into the cell density of $5 \times 10^{4} / \mathrm{ml}$, while the third-generation hypertrophic scar fibroblasts were treated into the cell density of $2 \times 10^{4} / \mathrm{ml}$. Co-culture group: Transwell co-culture plates with the inner membrane pore size of $0.4 \mathrm{pm}$ were selected and ADSCs and scar fibroblasts were co-cultured. ADSCs $(1 \mathrm{ml})$ with a density of $5 \times 10^{4} / \mathrm{ml}$ were added into the upper layer, while $1 \mathrm{ml}$ scar fibroblasts with a density of $2 \times 10^{4} / \mathrm{ml}$ were added into the lower layer using the non-contact co-culture mode. Control group: Scar fibroblasts $(1 \mathrm{ml})$ with a density of $2 \times 10^{4} / \mathrm{ml}$ were cultured in an ordinary 6 -well plate, and the medium was added until the volume was $2 \mathrm{ml}$. After the co-culture for 21 days, the cells were collected for subsequent experiments.

Detection of contents of collagen I and transforming growth factor- $\beta 1$ (TGF- $\beta 1$ ) using ELISA kit. The fibroblasts in experimental and control group were collected. After decomposition, they were centrifuged at $1,000 \mathrm{x}$ g for $10 \mathrm{~min}$; then the supernatant was taken into the Eppendorf (EP) tube to detect the contents of collagen I and TGF- $\beta 1$ in fibroblasts using the ELISA kit.

Detection of $m R N A$ expressions of $\alpha-S M A$ and $D C N$ via reverse transcription-polymerase chain reaction (RT-PCR). The fibroblasts in experimental and control group were collected. The total RNA was extracted from cells according to the instructions of RNA extraction kit, and the qualified total RNA was selected for reverse transcription in accordance with the instructions of reverse transcription kit. The specific reaction conditions were as follows: Incubation at 

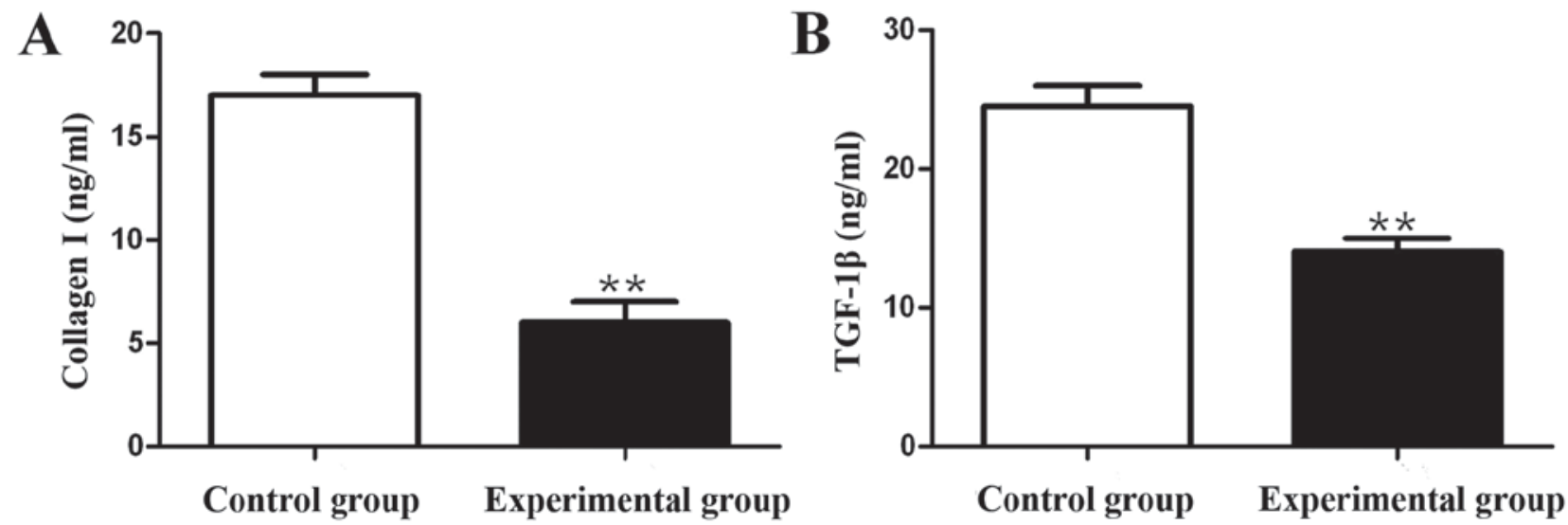

Figure 1. Detection of collagen I and TGF- $\beta 1$ contents using ELISA kit. (A) TGF- $\beta 1$ content. (B) TGF- $\beta 1$ content; *** $p<0.01$.

A

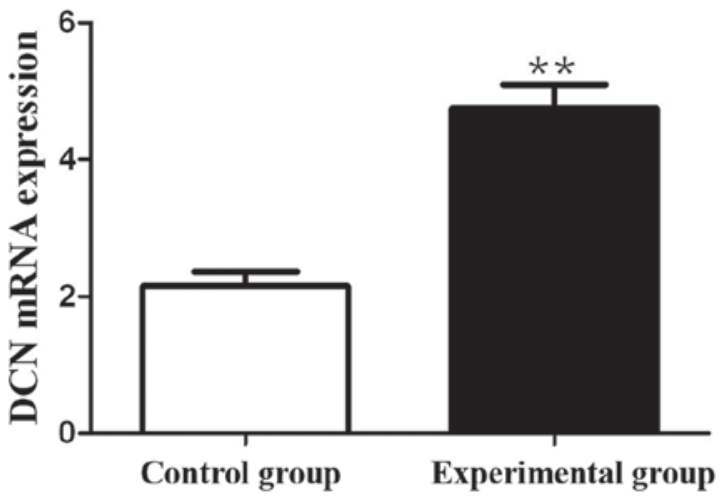

B

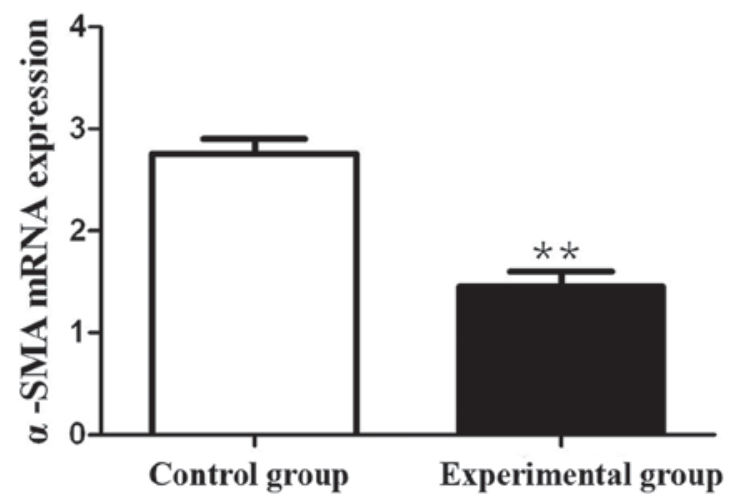

Figure 2. Detection of effects of ADSCs on mRNA expressions of $\alpha$-SMA and DCN in fibroblasts via RT-qPCR. (A) mRNA expression of DCN. (B) mRNA expression of $\alpha$-SMA; ${ }^{* *} \mathrm{p}<0.01$.

$42^{\circ} \mathrm{C}$ for $15 \mathrm{~min}$, incubation at $95^{\circ} \mathrm{C}$ for $3 \mathrm{~min}$; after that, the total RNA was cooled on ice and then stored in a refrigerator at $-80^{\circ} \mathrm{C}$ for subsequent experiment. The routine amplification was performed according to the primer sequences in Table I. With $\beta$-catenin as the internal control gene, $\mathrm{Cq}$ values were output from the instrument; the relative expression levels of $\alpha$-SMA and DCN mRNA were calculated using the $2^{-\Delta \Delta \mathrm{Cq}}$ method (8).

Detection of $\alpha$-SMA and DCN protein expressions via western blot analysis. The fibroblasts in experimental and control groups were collected, and the cells were resuspended using the cell lysis buffer, and cleaved on ice for $30 \mathrm{~min}$, followed by centrifugation at $12,000 \mathrm{x}$ g at $4^{\circ} \mathrm{C}$ for $15 \mathrm{~min}$. The supernatant was carefully absorbed as the total protein. After protein quantification using the BAC protein quantification kit, the loading buffer was added, $60 \mu \mathrm{g}$ proteins in each group were taken for $10 \%$ sodium dodecyl sulfate polyacrylamide gel electrophoresis (SDS-PAGE), and the proteins were transferred onto the polyvinylidene fluoride (PVDF) membrane. The membrane was sealed using Tris-buffered saline (TBS) containing 5\% skimmed milk at room temperature for $1 \mathrm{~h}$, primary antibodies with cat. nos. ab150301 and ab137508 both from Abcam, were added dropwise for incubation at $4^{\circ} \mathrm{C}$ overnight. On the next day, the membrane was washed with Tris-buffered saline Tween (TBST) for three times (15 min/time). Then secondary antibody, goat anti-mouse IgG-HRP (1:2,000; cat. no. ab6789; Abcam) was added for incubation at room temperature for $1 \mathrm{~h}$, followed by washing with TBST, luminous reaction using electrochemiluminescence (ECL) kit, image scanning and analysis, and gray scale analysis with glyceraldehyde-3phosphate dehydrogenase (GADPH) as the internal reference.

Detection of $\alpha-S M A$ and DCN protein expressions in fibroblasts via immunofluorescence assay. After the cells grew on the glass slide, they were fixed with pre-cooled paraformaldehyde, washed with PBS, permeated with $0.2 \%$ Triton X-100 for $10 \mathrm{~min}$, and washed again with PBS for three times; then cells were sealed with the serum of the same host for $30 \mathrm{~min}$, and washed with PBS for three times. The primary antibodies with cat. nos. ab150301 and ab137508 (Abcam) were added in the wet box overnight, and then cells were washed with PBS for three times, the secondary antibody with cat. no. ab6789 (Abcam) was added at room temperature for $2 \mathrm{~h}$ in a dark place, and washed again with PBS for three times. After nuclear staining with DAPI, they were photographed under fluorescence microscope (SZ61; Olympus Corporation, Tokyo, Japan). 

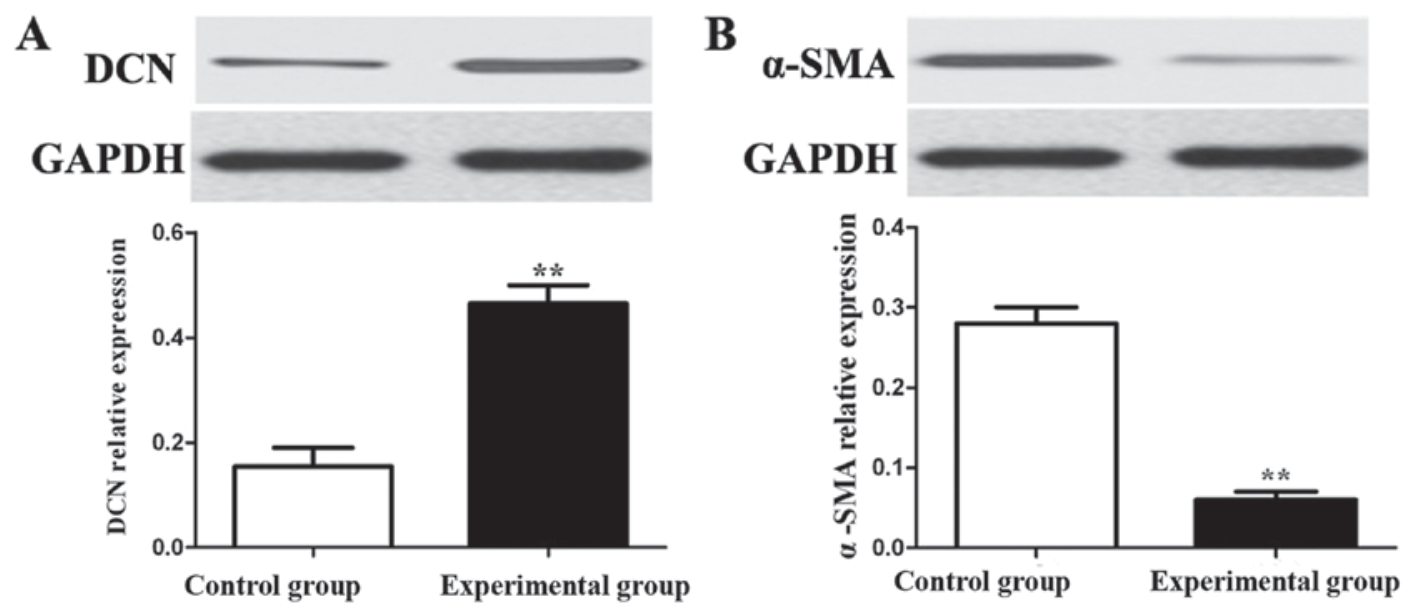

Figure 3. Detection of effects of ADSCs on protein expressions of $\alpha$-SMA and DCN in fibroblasts via western blot analysis. (A) Protein expression of DCN (B) Protein expression of $\alpha$-SMA; ${ }^{* *} \mathrm{p}<0.01$.

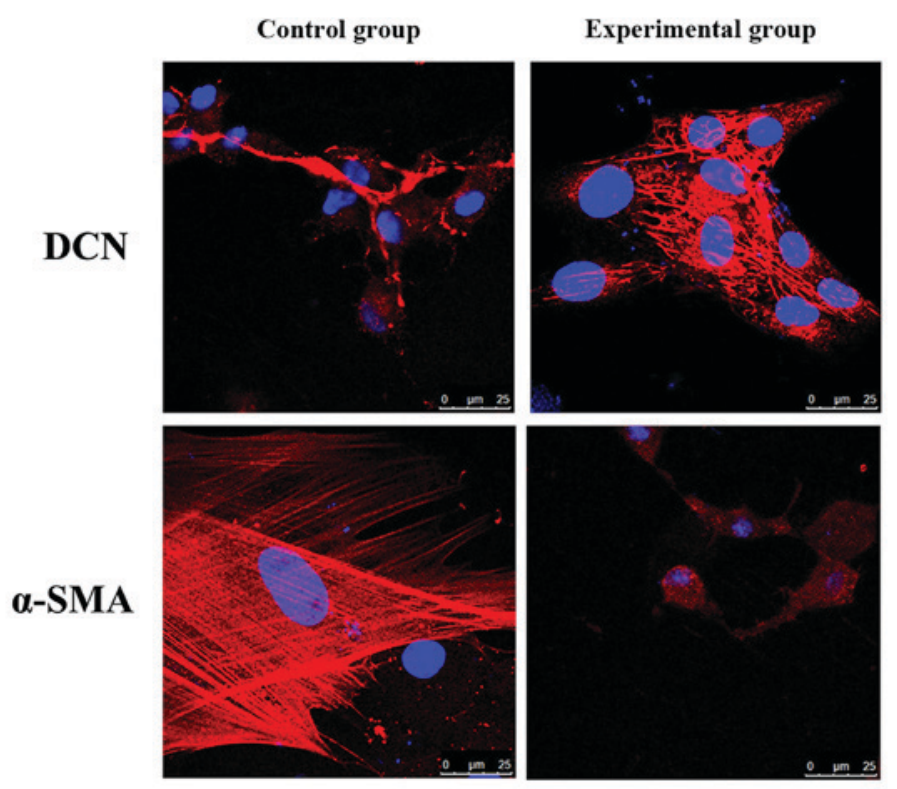

Figure 4. Detection of effects of ADSCs on protein expressions of $\alpha$-SMA and DCN in fibroblasts via immunofluorescence assay.

Statisticalanalysis. SPSS 17.0 software (SPSS, Inc., Chicago, IL, USA) was used for data processing in this study. Measurement data were presented as mean \pm standard deviation, and t-test was used for intergroup comparisons. Chi-square test was used for intergroup comparisons of enumeration data. $\mathrm{P} \leq 0.05$ suggested that the difference was statistically significant.

\section{Results}

Effects of ADSCs on collagen I and TGF- $\beta 1$ contents in fibroblasts. Compared with those in control group, the content of collagen I was decreased by $65.7 \%$ and the content of TGF- $\beta 1$ was decreased by $39.8 \%$ in experimental group, and the differences were statistically significant $(\mathrm{p}<0.01)$ (Fig. 1).

Effects of ADSCs on mRNA expressions of DCN and $\alpha-S M A$ in fibroblasts. RT-PCR was performed to detect the effects of ADSCs on mRNA expressions of DCN and $\alpha$-SMA in fibroblasts. The results showed that compared with those in control group, the mRNA expression of DCN in fibroblasts in experimental group was significantly increased $(\mathrm{p}<0.01)$, but the mRNA expression of $\alpha$-SMA was significantly decreased $(\mathrm{p}<0.01)$ (Fig. 2).

Detection of effects of ADSCs on protein expressions of $\alpha-S M A$ and DCN in fibroblasts via western blot analysis. Western blot analysis was performed to detect the effects of ADSCs on protein expressions of $\alpha$-SMA and DCN in fibroblasts. The results showed that compared with those in control group, the protein expression of DCN in fibroblasts in experimental group was obviously increased $(\mathrm{p}<0.01)$, but the protein expression of $\alpha$-SMA was obviously decreased $(\mathrm{p}<0.01)$ (Fig. 3).

Detection of effects of ADSCs on protein expressions and distribution of $\alpha-S M A$ and DCN in fibroblasts via 
immunofluorescence assay. The effects of ADSCs on protein expressions and distribution of $\alpha$-SMA and DCN in fibroblasts were detected via immunofluorescence assay. The results showed that compared with those in control group, the protein expression of DCN in fibroblasts in experimental group was significantly increased, but the protein expression of $\alpha$-SMA was significantly decreased (Fig. 4).

\section{Discussion}

When the skin tissue undergoes trauma repair, scar formation is unavoidable. The mechanism of scar formation is not yet fully elucidated at present, but its histological features are characterized by hyperplasia of fibroblasts and higher synthesis rate of extracellular matrix than degradation rate (9). At present, the clinical treatment means of hypertrophic scar are not uniform, and the effects are unsatisfactory (10). So the further study on its treatment mechanism and new treatment program has become one of the hot spots.

Hypertrophic scars are caused by excessive healing of dermal fibrosis cell. Dermal fibroblasts are in hyperplasia during post-traumatic repair, the synthesis rate of extracellular matrix is significantly greater than the degradation rate, and the inflammation exists in the wound, so the combined action of these factors leads to the pathological scars $(11,12), \alpha-S M A$ is the cytoskeletal protein that binds to fibrin and exerts contraction. At normal levels, $\alpha$-SMA is widely distributed in muscle and vascular smooth muscles, but the expression of $\alpha$-SMA is increased in the abnormal conditions and it promotes the maturation of myofibroblasts. Besides, $\alpha$-SMA can not only promote wound healing, but also synthesize and secrete a large number of collagens, growth factors and enzymes. When the balance between secretion and degradation of extracellular matrix is broken, pathological scar can appear (13). In addition, fibroblasts can also synthesize DCN. As one of the most important proteoglycans in normal dermis, DCN is a kind of extracellular small-molecular complex rich in leucine, composed of core protein and polysaccharose. Core protein is the most critical in DCN, which can transmit different biological signals and resist the scar generation. Studies have shown that DCN can significantly inhibit the proliferation of fibroblasts (14). Similarly, some studies have revealed that DCN binds to TGF- $\beta 1$ to significantly reduce its activity, thereby inhibiting the activity of fibroblasts and reducing the occurrence of fibrosis. When the content of DCN is reduced in the dermal cell layer is reduced, the scar hyperplasia will be obvious (15). DCN can inhibit the fibroblast activity in skin tissues, and the increased DCN content in human lung fibroblasts can also reduce the activity of $\alpha$-SMA and exert the anti-fibrosis effect (16). Under physiological conditions, collagen fibers are arranged normally in a reticular structure, and the collagen metabolism and deposition are in a balanced state; but in hypertrophic scars, the expression of collagen I is significantly increased, other components in extracellular matrix are fewer, and the collagen deposition is excessive with different arrangement state $(17,18)$.

In this experiment, after the rabbit ear hypertrophic scar model was established successfully, the fibroblasts of hypertrophic scar tissues in rabbit ears were separated and cultured using the mechanical method combined with enzyme digestion, and the ADSCs and scar fibroblasts were cultured in non-contact Transwell co-culture system for 21 days (experimental group); the corresponding scar fibroblasts were cultured in an ordinary 6-well plate without any treatment for 21 days (control group). The results of ELISA showed that the content of collagen I in experimental group was significantly decreased compared with that in control group, which were consistent with the research results in the scar formation after burn $(19,20)$, suggesting that skin wound regeneration is closely related to the increased content of collagen I, and reducing the collagen I expression may play an important role in the prevention and treatment of scar. The results of RT-PCR and western blot analysis revealed that the mRNA and protein expressions of $\alpha$-SMA in experimental group were significantly decreased, while those of DCN were significantly increased. Immunofluorescence assay showed that the expression of $\alpha$-SMA was obviously decreased, while the expression of DCN was significantly increased in experimental group. Studies have shown that the main mechanism of hypertrophic scar is not the decline in degradation, but the synthesis capability of scar collagen far outweighing the degradation capability, accompanied by the decreased DCN synthesis and significantly increased expression of $\alpha$-SMA (21).

In conclusion, ADSCs can inhibit the mRNA and protein expressions of $\alpha$-SMA and promote the mRNA and protein expressions of DCN in in vitro culture system, suggesting that they are expected to be used in the prevention and treatment of pathological scars.

\section{Acknowledgements}

Not applicable.

\section{Funding}

No funding was received.

\section{Availability of data and materials}

The datasets used and/or analyzed during the present study are available from the corresponding author on reasonable request.

\section{Authors' contributions}

HC and YW contributed to the conception of the study. XW contributed significantly to data analysis and manuscript preparation. XS performed the data analyses and wrote the manuscript. HL and XL helped perform the analysis with constructive discussions. All authors read and approved the final manuscript.

\section{Ethics approval and consent to participate}

The study was approved by the Ethics Committee of Jining First People's Hospital (Jining, China).

\section{Patient consent for publication}

Not applicable. 


\section{Competing interests}

Authors declare they have no competing interests.

\section{References}

1. Kim S, Choi TH, Liu W, Ogawa R, Suh JS and Mustoe TA Update on scar management: Guidelines for treating Asian patients. Plast Reconstr Surg 132: 1580-1589, 2013.

2. Zuk PA, Zhu M, Ashjian P, De Ugarte DA, Huang JI, Mizuno H, Alfonso ZC, Fraser JK, Benhaim P and Hedrick MH: Human adipose tissue is a source of multipotent stem cells. Mol Biol Cell 13: 4279-4295, 2002.

3. Wang G, Ren Y, Cao W, Yang Y and Li S: Liposculpture and fat grafting for aesthetic correction of the gluteal concave deformity associated with multiple intragluteal injection of penicillin in childhood. Aesthetic Plast Surg 37: 39-45, 2013.

4. Guisantes E, Fontdevila J and Rodríguez G: Autologous fat grafting for correction of unaesthetic scars. Ann Plast Surg 69: $550-554,2012$.

5. Klinger M, Marazzi M, Vigo D and Torre M: Fat injection for cases of severe burn outcomes: A new perspective of scar remodeling and reduction. Aesthetic Plast Surg 32: 465-469, 2008.

6. Kim WS, Park BS, Sung JH, Yang JM, Park SB, Kwak SJ and Park JS: Wound healing effect of adipose-derived stem cells: A critical role of secretory factors on human dermal fibroblasts. J Dermatol Sci 48: 15-24, 2007.

7. Bruno A, Delli Santi G, Fasciani L, Cempanari M, Palombo M and Palombo P: Burn scar lipofilling: Immunohistochemical and clinical outcomes. J Craniofac Surg 24: 1806-1814, 2013.

8. Livak KJ and Schmittgen TD: Analysis of relative gene expression data using real-time quantitative PCR and the 2(-Delta Delta C(T)) method. Methods 25: 402-408, 2001

9. Derfoul A, Perkins GL, Hall DJ and Tuan RS: Glucocorticoids promote chondrogenic differentiation of adult human mesenchymal stem cells by enhancing expression of cartilage extracellular matrix genes. Stem Cells 24: 1487-1495, 2006.

10. Le Blanc K, Frassoni F, Ball L, Locatelli F, Roelofs H, Lewis I, Lanino E, Sundberg B, Bernardo ME, Remberger M, et al; Developmental Committee of the European Group for Blood and Marrow Transplantation: Mesenchymal stem cells for treatment of steroid-resistant, severe, acute graft-versus-host disease: A phase II study. Lancet 371: 1579-1586, 2008.
11. Sensebé L, Krampera M, Schrezenmeier H, Bourin P and Giordano R: Mesenchymal stem cells for clinical application. Vox Sang 98: 93-107, 2010.

12. Varkey M, Ding J and Tredget EE: Differential collagen-glycosaminoglycan matrix remodeling by superficial and deep dermal fibroblasts: Potential therapeutic targets for hypertrophic scar. Biomaterials 32: 7581-7591, 2011.

13. Li NY, Chen F, Dikkers FG and Thibeault SL: Dose-dependent effect of mitomycin $\mathrm{C}$ on human vocal fold fibroblasts. Head Neck 36: 401-410, 2014.

14. King SN, Chen F, Jetté ME and Thibeault SL: Vocal fold fibroblasts immunoregulate activated macrophage phenotype. Cytokine 61: 228-236, 2013.

15. Bi X, Tong C, Dockendorff A, Bancroft L, Gallagher L, Guzman G, Iozzo RV, Augenlicht LH and Yang W: Genetic deficiency of decorin causes intestinal tumor formation through disruption of intestinal cell maturation. Carcinogenesis 29: 1435-1440, 2008

16. Liu BH, Chen L, Li SR, Wang ZX and Cheng WG: Smac/DIABLO regulates the apoptosis of hypertrophic scar fibroblasts. Int J Mol Med 32: 615-622, 2013.

17. Siebert JW, Burd AR, McCarthy JG, Weinzweig J and Ehrlich HP: Fetal wound healing: A biochemical study of scarless healing. Plast Reconstr Surg 85: 495-502, discussion 503-504, 1990.

18. Sander EA, Barocas VH and Tranquillo RT: Initial fiber alignment pattern alters extracellular matrix synthesis in fibroblast-populated fibrin gel cruciforms and correlates with predicted tension. Ann Biomed Eng 39: 714-729, 2011.

19. Deitch EA, Wheelahan TM, Rose MP, Clothier J and Cotter J: Hypertrophic burn scars: Analysis of variables. J Trauma 23: 895-898, 1983.

20. Zhang K, Garner W, Cohen L, Rodriguez J and Phan S: Increased types I and III collagen and transforming growth factor-beta 1 mRNA and protein in hypertrophic burn scar. J Invest Dermatol 104: 750-754, 1995.

21. Martinez FO, Helming L and Gordon S: Alternative activation of macrophages: An immunologic functional perspective. Annu Rev Immunol 27: 451-483, 2009. International (CC BY-NC-ND 4.0) License. 